\title{
Germline Stem Cells
}

\author{
Allan Spradling ${ }^{1}$, Margaret T. Fuller ${ }^{2,3}$, Robert E. Braun ${ }^{4}$, and Shosei Yoshida ${ }^{5}$ \\ ${ }^{1}$ Howard Hughes Medical Institute Research Laboratories, Department of Embryology, Carnegie Institution, \\ Baltimore, Maryland 21218 \\ ${ }^{2}$ Department of Developmental Biology, Stanford University School of Medicine, Stanford, California \\ 94305-5329 \\ ${ }^{3}$ Department of Genetics, Stanford University School of Medicine, Stanford, California 94305-5329 \\ ${ }^{4}$ The Jackson Laboratory, Bar Harbor, Maine 04609 \\ ${ }^{5}$ Division of Germ Cell Biology, National Institute for Basic Biology, 5-1 Higashiyama, Myodaiji, Okazaki, \\ Aichi 444-8787, Japan \\ Correspondence: mtfuller@stanford.edu
}

\begin{abstract}
Sperm and egg production requires a robust stem cell system that balances self-renewal with differentiation. Self-renewal at the expense of differentiation can cause tumorigenesis, whereas differentiation at the expense of self-renewal can cause germ cell depletion and infertility. In most organisms, and sometimes in both sexes, germline stem cells (GSCs) often reside in a defined anatomical niche. Factors within the niche regulate a balance between GSC self-renewal and differentiation. Asymmetric division of the germline stem cell to form daughter cells with alternative fates is common. The exception to both these tendencies is the mammalian testis where there does not appear to be an obvious anatomical niche and where GSC homeostasis is likely accomplished by a stochastic balance of selfrenewal and differentiation and not by regulated asymmetric cell division. Despite these apparent differences, GSCs in all organisms share many common mechanisms, although not necessarily molecules, to guarantee survival of the germline.
\end{abstract}

In males and in females or hermaphrodites of many species, gametes are produced throughout reproductive life from adult stem cells dedicated to the germline. Some remarkably conserved themes as well as intriguing differences are beginning to emerge from studies of germline stem cells (GSCs) in the Caenorhabditis elegans gonad, Drosophila ovary, and testes from Drosophila and mice. GSCs commonly reside in a special microenvironment, a stem cell niche, provided by somatic support cells.
GSCs in this niche both self-renew to maintain the generative population and also produce progeny germ cells that exit the niche and begin the process of differentiation. These progeny commonly execute several rounds of mitotic division before switching to the germ cellspecific cell cycle of meiosis and subsequent differentiation into mature gametes (see Kimble 2011). A strongly conserved feature is that the mitotic divisions are incomplete, so that permanent cytoplasmic bridges connect mitotic

Editors: Paolo Sassone-Corsi, Margaret T. Fuller, and Robert Braun

Additional Perspectives on Germ Cells available at www.cshperspectives.org

Copyright (C) 2011 Cold Spring Harbor Laboratory Press; all rights reserved; doi: 10.1101/cshperspect.a002642

Cite this article as Cold Spring Harb Perspect Biol 2011;3:a002642 
A. Spradling et al.

sisters descended from a single founder cell, forming a cyst of germ cells that develop in synchrony (see Greenbaum et al. 2011). Communication between germline and special somatic cells plays important roles in both stem cell maintenance and in germ cell proliferation and differentiation, as well as in the genesis of GSCs from primordial germ cells (PGCs) in the gonad. GSCs are normally unipotent, producing only differentiating gametes. However, as the only adult stem cells that contribute to the next generation, it is likely that GSC potency must be strictly controlled to prevent teratoma formation. Moreover, these controls likely differ between the sexes, reflecting the profound differences between male and female gametogenesis. In this article, we examine these intriguing characteristics of germline stem cells emerging from research on model organisms from invertebrates to mammals.

Germline stem cells, especially from C. elegans and Drosophila, are among the best understood adult stem cell types, and have provided important models for study of the regulation of adult stem cell behavior in vivo. The hallmarks of adult stem cells are a committed but relatively undifferentiated state, a long-term ability to proliferate, and an ability to produce both new stem cells (self-renewal) and differentiating progeny. Adult stem cell lineages are responsible for long-term maintenance and repair of tissues containing highly specialized, short-lived cell types, including blood, skin, and the epithelium of the intestine and colon, as well as sperm. Differentiated cells in many other tissues, including breast, lung, skeletal muscle, bladder, and prostate, are also produced from adult stem cells in response to physiological changes or damage. The mechanisms that regulate adult stem cell self-renewal and the proliferation and differentiation of stem cell progeny are key not only for harnessing the potential of adult stem cells for regenerative medicine, but also for understanding the developmental origins of cancer. Many common cancers arise in adult stem cell lineages, and there is increasing evidence that defects in the mechanisms that regulate self-renewal, proliferation, and differentiation in adult stem cell lineages can contribute to oncogenesis. Thus, the tremendous recent advances in understanding how the local microenvironment of the stem cell niche regulates self-renewal and differentiation of germline stem cells have important implications for somatic biology as well as for the germline.

\section{GERMLINE STEM CELL LINEAGES}

Germline stem cells produce progeny that proliferate through several rounds of divisions, and then enter meiosis (Fig. 1). Although this transit-amplifying (TA) strategy is widely conserved in spermatogenesis, the germline mitotic proliferation program appears very different from the perspective of the female. Although female germline stem cells produce daughter cells that initiate differentiation with rounds of mitotic division, producing cysts of interconnected mitotic sisters in both Drosophila and mice (Pepling and Spradling 1998, 2001), these divisions are not TA, because the number of oocytes is not amplified. The TA program likely underlies germ cell behavior in both sexes, but the strategy has been modified during evolution in the female so that most of the mitotic sisters sacrifice their contents to build the specialized oocyte. This sex difference goes along with two other main differences in germ cells between the sexes. (1) The female gamete is larger and usually contains extensive components to carry out the start of embryogenesis (see Von Stetina and Orr-Weaver 2011). (2) The meiotic divisions take place after the major events of gametogenesis in females but before the major morphogenetic events that lead to the final form of the gametes in males.

\section{GERMLINE STEM CELL POPULATIONS MAINTAINED BY INSTRUCTIONS FROM A LOCAL NICHE}

Germline stem cells reside in a special microenvironment that restricts their differentiation. A classic example occurs in C. elegans, where a large somatic cell at the distal tip of the gonad maintains a syncytial population of mitotically proliferating germ cell nuclei through 
Germline Stem Cells

A

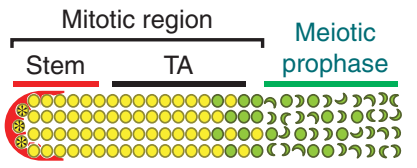

B

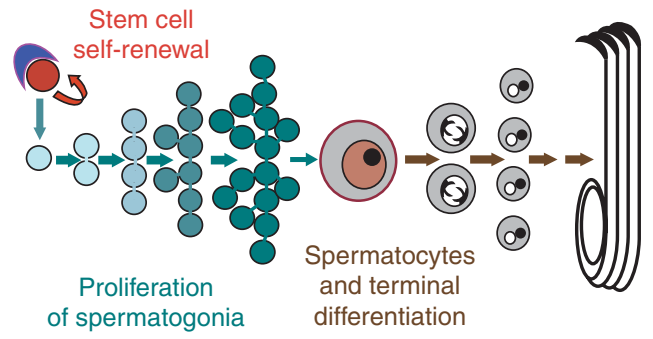

C

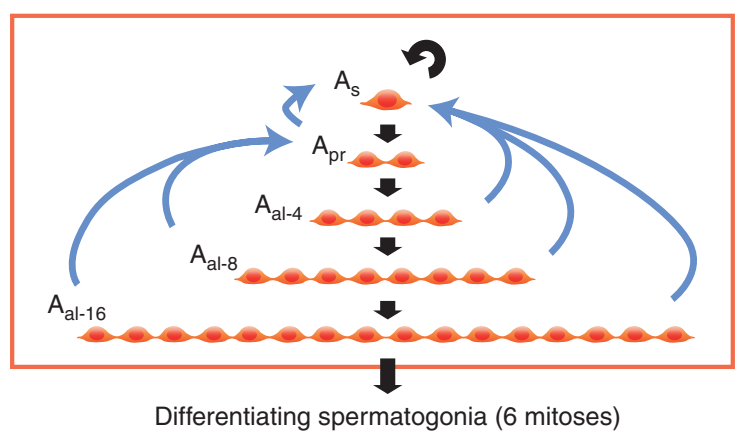

Differentiating spermatogonia (6 mitoses)

Spermatocytes (meiosis)

Spermatids (haploid)

Spermatozoa

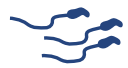

Figure 1. Germline stem cell lineages: stem cell self-renewal, transit-amplifying (TA) mitotic divisions, and the switch to meiosis and gamete differentiation. (A) Germline stem cell lineage in a C. elegans hermaphrodite undergoing oogenesis. The somatic distal tip cell (DTC, red) maintains a population of germ cell nuclei in a stem cell state. As germ cell nuclei move away from the DTC they enter a mitotic TA state during which they gradually differentiate, finally switching to the meiotic program (green). (Panel adapted from Cinquin et al. [2010]; reprinted, with permission, from the National Academy of Sciences (C) 2010.) (B) Male germline stem cell lineage in Drosophila. A stem cell (red) at the tip of the testis divides asymmetrically, producing a new stem cell and a gonialblast, which initiates four rounds of synchronous spermatogonial mitotic TA divisions with incomplete cytokinesis. The resulting 16 interconnected germ cells undergo premeiotic DNA replication in synchrony and switch to the spermatocyte program of cell growth, meiotic prophase, and transcription of terminal differentiation genes. (All 16 cells become spermatocytes, but only one is shown for simplicity.) (C) Male germline stem cell lineage in mouse. In mice, the prevailing model (shown by black arrows) assumes that the singly isolated spermatogonia $\left(\mathrm{A}_{\mathrm{s}}\right)$ is the predominant stem cell during steady-state spermatogenesis. However, all of the cells shown in the box, the $A_{s}, A_{p r}$ and $A_{a l}$ spermatogonia have stem cell potential. At the 16 cell-cyst stage, the $\mathrm{A}_{\mathrm{al}-16}$ transform without cell division into differentiating spermatogonia, which subsequently undergo six rounds of mitosis before entering meiosis. The blue arrows indicate the ability of cells to detach from cysts and revert to the $A_{s}$ state. Reversion occurs frequently during regeneration following insult and following germ cell transplantation, however, it has also been observed during steady-state spermatogenesis. (Panel $B$ is adapted from Davies and Fuller [2008]; reprinted, with permission, from Cold Spring Harbor Press (C) 2008.) 
A. Spradling et al.

close-range instruction via Notch pathway signaling (Austin and Kimble 1987). The subpopulation of the germline mitotic nuclei lying closest to the distal tip likely correspond to germline stem cells (Cinquin et al. 2010), whereas the mitotic nuclei lying further from the distal tip likely correspond to the TA population (Fig. 1A). The biology of C. elegans germline stem cells and their mitotic progeny is discussed in detail in Kimble (2011).

\section{THE DROSOPHILA OVARIAN GERMLINE STEM CELL NICHE}

Drosophila females maintain germ cell production throughout adult life by establishing a niche at the tip of each ovariole that prevents some PGCs from differentiating. The ability to form niches appears to distinguish species with female GSCs from those without rather than basic differences in germ cell differentiation. Niches in the ovary arise near the end of larval development and upload PGCs, which are produced in excess (Gilboa and Lehmann 2006), just prior to the onset of global differentiation signals. PGCs that make it into the niche are protected and become GSCs, whereas identical PGCs outside begin development (Gilboa and Lehmann 2004). In addition to sequestering a supply of undifferentiated germ cells, niches program subsequent GSC divisions to be asymmetric by providing only enough room for one of the two daughters to remain inside. In so simple a manner, GSC niches generate a lifelong supply of germ cells for egg production. The niche itself is built from three somatic cell types: terminal filament cells located at the anterior of each ovariole, cap cells, which actually contact GSCs and hold them in the niche, and escort cells, which wrap thin processes around GSCs and prevent direct GSC-GSC contact (Fig. 2A).

Genes promoting PGC/GSC differentiation are modulated by changes at the level of chromatin structure, transcription, and RNA processing, but especially at the level of translation. The conserved NANOS and PUMILIO translational repressors are essential to prevent premature germ cell differentiation (Lin and Spradling
1997; Forbes and Lehmann 1998; Wang and Lin 2004), indicating that messenger RNAs (mRNAs) capable of promoting cyst formation and oogenesis are present within PGCs. These mRNAs are controlled by proteins, including VASA, which localize them within large silencing ribonucleoprotein particles (RNPs), promote CCR4-meditated deadenylation, and which influence their binding to $40 \mathrm{~S}$ small ribosomal subunits in conjunction with translation initiation factors such as eIF4E (Wang and Lin 2004; Fichelson et al. 2009; Liu et al. 2009; see Kugler and Lasko 2009). MicroRNAs (miRNAs) contribute to both GSC maintenance and likely provide sequence specificity to orchestrate the complex, multistep program of gametogenesis following activation (Forstemann et al. 2005; Hatfield et al. 2005; Jin and Xie 2007; Park et al. 2007; Yang et al. 2007a,b). Indeed, the perinuclear nuage, stage-specific nuclear and cytoplasmic germ granules, and chromatoid bodies that typify germ cells throughout the metazoa, are manifestations of abundant RNA processing complexes participating in germ cell regulation (Kotaja and Sassone-Corsi 2007; Lim and Kai 2007; Klattenhoff and Theurkauf 2008; Lin et al. 2008; Soper et al. 2008; see Voronina et al. 2011).

Drosophila ovarian niches control the onset of germ cell development by spatially modulating expression of a high-level differentiation inducer encoded by bag-of-marbles (bam). Cap cells and possibly anterior escort cells activate JAK-STAT signaling upon receipt of the unpaired ligand from terminal filament cells and respond by producing the BMP ligands Dpp and Gbb (López-Onieva et al. 2008; Wang et al. 2008). Consequently, germ cells located within a small zone adjacent to the cap cells are positioned to receive a strong BMP signal. Activation of BMP receptors in GSCs directly represses bam transcription (Chen and McKearin 2003). Only upon leaving the niche do they escape BMP-mediated repression, up-regulate bam expression, and become cystoblasts, i.e., cells that will found new 16-cell cysts. bam can initiate development equally well within larval ovarian PGCs, but premature differentiation is prevented by 


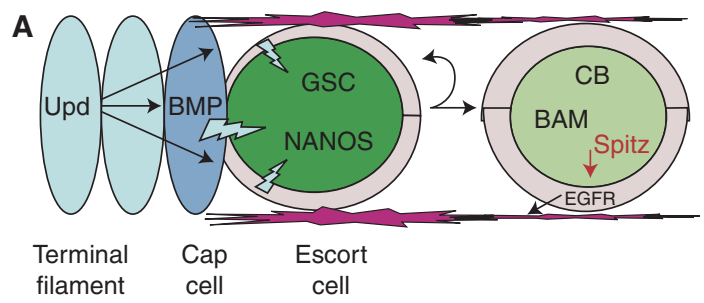

B

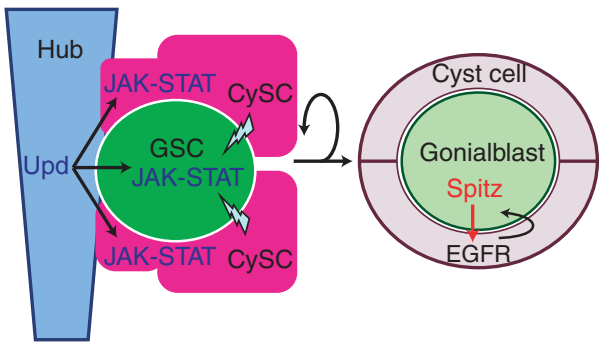

C $\Gamma$

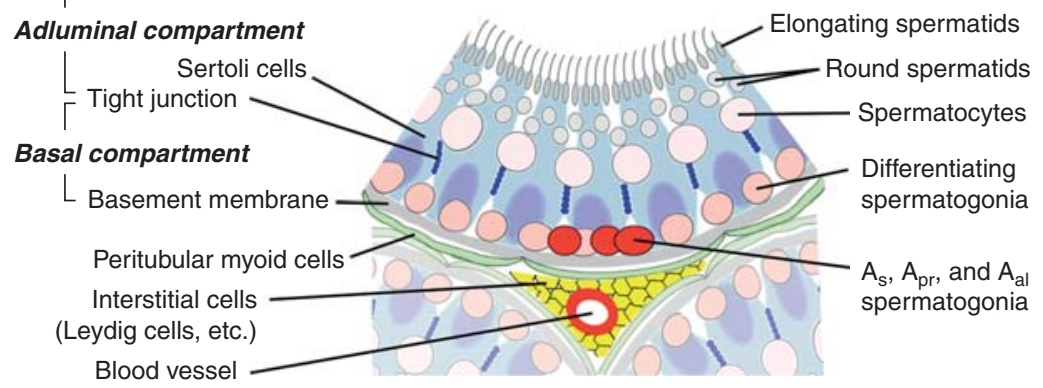

Figure 2. Germline stem cell microenvironments in Drosophila ovary and Drosophila and mouse testes. $(A)$ The Drosophila ovarian stem cell niche controls cystoblast formation. Upd secreted by terminal filament cells (light blue) activates JAK-STAT signal transduction within cap cells (dark blue) and probably in escort cells (tan), which in response produce the BMP ligands DPP and GBB ("BMP”). Receipt of these signals in germline stem cells (GSC) activates BMP signal transduction (lightning blots), which represses bam transcription. Consequently, the NANOS translational repressor remains high. (Right) A GSC daughter has differentiated into a cystoblast (CB, light green) and is surrounded by escort cells. High levels of BAM present due to derepression have translationally downregulated NANOS. Signals from the CB via the ligand Spitz (red arrow) activate EGFR signaling in escort cells, which modulate the extracellular matrix (red lines) to block residual BMP reception. (B) The apical hub and flanking somatic cyst stem cells (CySCs) contribute to the germline stem cell (GSC) niche in Drosophila testes. (Left) Unpaired (Upd) secreted by hub cells (blue) activates the Janus kinase-signal transducer and activator transcription (JAK-STAT) pathway, which requires the cell to autonomously maintain the attachment of GSCs to the hub and for self-renewal of cyst stem cells (CySC). GSC self-renewal also requires as-yet-unknown signal(s) (lightning bolt) from the CySCs. (Right) Interactions between the progeny of somatic and germline stem cells set up the functional unit of differentiation, the cyst. A gonialblast (light green), produced by asymmetric division of a GSC, signals via the epidermal growth factor receptor (EGFR) ligand Spitz, to cyst cells (light pink) produced by asymmetric division of CySCs. Activation of EGFR triggers the somatic cyst cells to envelop the gonialblast and may also induce changes in gene expression in the cyst cells required for the germ cells to execute the TA division program. $(C)$ The microenvironment of germline stem cells in mouse testes. All spermatogonia, including the GSCs, occupy the basal compartment of the seminiferous tubules between Sertoli cell tight junctions and the basement membrane. The GSCs are biased to the area adjacent to the blood vessels and interstitial cells running between the tubules. (Panel $C$ is adapted from Davies and Fuller [2008]; reprinted, with permission, from Cold Spring Harbor Press (C) 2008.) 
A. Spradling et al.

gonad-wide BMP signaling during these stages (Gilboa and Lehmann 2004; Kai and Spradling 2004). Interestingly, the bam gene is not widely conserved and shows signs of recent positive selection (Civetta et al. 2006), raising the possibility that it arose in concert with the evolution of Drosophila female GSCs.

A key niche requirement is to limit highlevel Dpp/Gbb signaling to a one-cell-wide zone so that one daughter of each GSC division will be forced out, derepress bam, and become a cystoblast. The DALLY heparin sulfate glycoprotein, which accumulates at high levels only around the cap cells, binds to and stabilizes Dpp and may be necessary to effectively activate BMP signaling (Guo and Wang 2009; Hayashi et al. 2009). EGFR signaling from early germ cells to escort cells mediated by the membrane protease STET influences DALLY levels or function (Schulz et al. 2002; Liu et al. 2011). The ability of germ cells downstream from the niche to receive BMP signals is further controlled by negative feedback from the BMP-induced E3 ubiquitin ligase SMURF and the Ser/Thr kinase FUSED, which promotes turnover of the BMP receptor THICK VEINS (Tkv) (Casanueva and Ferguson 2004; Xia et al. 2010). All these mechanisms ensure that once outside the niche, bam transcription will be promptly and stably activated.

Bam brings about cyst formation by promoting the translation of differentiation-promoting transcripts (Li et al. 2009) and reducing E-CADHERIN (E-cad) expression to ensure that cystoblasts do not reenter the niche (Shen et al. 2009). Forming a complex with BENIGN GONIAL CELL NEOPLASM (BGCN), BAM interacts with eIF4A and other translation factors to modulate the expression of an unknown number of target mRNAs (Shen et al. 2009). The RNA-binding protein SXL, which controls sex-specific splicing in somatic cells, is also essential for cystoblast development (Chau et al. 2009). Changes in miRNA levels and activity assist in the translational changes. Within the niche, miRNAs initially help repress differentiation gene transcripts, because mutations abolishing miRNA function cause GSC loss. Following niche exit, miR-184 down-regulates the DPP receptor SAX to help maintain BAM production (Iovino et al. 2009). MEI-P26 modulates cyst growth by down-regulating repressive miRNAs, and up-regulating growthpromoting miRNAs such as bantam (Neumuller et al. 2008). MEI-P26 production in early cysts is itself translationally stimulated by VASA, which binds to a U-rich site in the meiP26 $3^{\prime}$ untranslated region (UTR) (Liu et al. 2009). miR-7 can repress bam translation and its negative control by maelstrom may help ensure appropriate cyst growth and stability (Pek et al. 2009).

Residence within the niche is governed by how strongly GSCs associate with cap cells via adherens junctions. This critical function is modulated in part by BAM/BGCN-mediated repression of E-cad mRNA translation (Shen et al. 2009). GSCs must adhere strongly enough to minimize loss, but not so tightly that the niche fills up with defective or prematurely differentiating cells. Adhesion levels within the niche respond to systemic insulin signaling and decline with age (LaFever and DrummondBarbosa 2005; Hsu and Drummond-Barbosa 2009). Even more intriguing is the possibility that competition for niche association might maintain stem cell quality by ensuring that weakened cells are expelled (Nystul and Spradling 2007; Johnston 2009; Rhiner et al. 2009). Bam (or BGCN) mutant germ cells lack E-cad translational repression, up-regulate E-cad levels, and displace wild-type GSCs from the niche (Jin et al. 2008). Feedback regulation likely ensures the prompt exit of GSCs that have prematurely activated bam, but so far evidence for more general competition is lacking.

\section{THE PHYLOGENETIC DISTRIBUTION OF FEMALE GERMLINE STEM CELLS}

There is a widespread misconception that adult female germline stem cells are common in "lower" organisms such as invertebrates and fish, but absent in "higher" forms such as mammals. In reality, we know relatively little about the phylogenetic distribution of adult female GSCs, because like other stem cells they are difficult to document using classical techniques. 
Nonetheless, available information strongly argues that species with adult female GSCs are rare across the phylogenetic spectrum. Indeed, mice and humans are typical of a wide range of invertebrate and vertebrate groups in which germ cell mitotic activity (whether from stem cell or cyst-forming divisions) is limited to preadult stages.

The diverse orders of insects have been investigated most widely (reviewed in Büning 1994). Oogenesis in these groups shows many common features, including terminal filaments, ovarioles, cysts (in many but not all groups), and follicle formation. Among this vast array of species, only in Drosophila and closely related flies have GSCs been clearly documented histologically in adult females. In other groups, ovarian mitotic germ cell divisions have not been found in adult stages. Surprisingly, even species with highly prolific females lack readily demonstrable GSCs within their adult germaria. Honeybee queens store more than one million viable sperm and individually maintain colonies containing 80,000 short-lived workers over multiple years. Yet honeybee germaria, which are highly elongated compared to Drosophila, lack readily identifiable GSCs. Still larger colonies numbering in the millions are sustained by some termite queens, who can live up to 50 years. Of course these queens and females from many other species may contain adult stem cells that have yet to be recognized. Nonetheless, the absence of Drosophila-like niches and their associated GSCs in most groups suggests that there may be evolutionary tradeoffs in maintaining adult female GSCs that have rarely proved favorable.

At least some noninsect species do maintain GSC activity into adulthood. In hydrozoans and planarians, circulating pleuripotent stem cells known as interstitial cells or neoblasts, replenish germ cells throughout life. C. elegans hermaphrodites maintain ongoing germ cell production. In vertebrates, adult female GSCs have been documented in a fish, medaka, where they reside in tubelike "cradles" that resemble a Drosophila germarium tip (Nakamura et al. 2010). Disrupting nanos1-gene function blocks ongoing follicle production in zebrafish (Draper et al.
2007). Outside of fish, there is currently no convincing evidence for vertebrate adult ovarian GSCs, despite contrary claims (Tilly et al. 2009). In principle, it is not difficult to recognize stem cell activity and ongoing follicle production based on histological studies. New follicles develop from a stem cell over many days, even in Drosophila where nurse cells speed development, ensuring that many downstream intermediates will be present whenever GSCs are active. In mice, mitotic germline divisions prior to meiosis, germline cysts, and germ cells with recombining meiotic chromosomes are all abundant during fetal development, but disappear shortly after birth ( for example, see Pepling and Spradling 2001; Matzuk et al. 2011). Ultimately, demonstrating the existence of adult ovarian GSCs requires the same proof needed for identifying any stem cell. Within the intact organism, such GSCs must be lineage-labeled, shown to self-renew, and their daughter cells must be shown to develop into fertile oocytes. Demonstrating that gametes can be produced following selection in cell cultures is not definitive because cells may have undergone reprogramming (Zou et al. 2009).

Why are female GSCs apparently so rare, despite the fact that major processes of female germ cell development have been conserved during evolution? The strategy of preserving some PGCs in a niche seems simple, and male GSCs are spread widely throughout phylogenetic space. We speculate that the rarity of adult female GSCs results from the profound differences between male and female gametes. Beyond the nucleus, sperm are basically throwaway devices. What organelles remain following spermiogenesis are likely damaged by the oxidative by-products of sperm activity prior to fertilization, and either fail to enter the egg or are quickly degraded. In contrast, the oocytes of metazoans that produce relatively few progeny, such as flies and mice, must contain cellular constituents of sufficient quality to ensure that the next generation starts out with no greater load of damage than was present a generation earlier. The difficulty of this task has been discussed mostly in terms of the mitochondria and their multicopy, easily mutated DNA 
A. Spradling et al.

genome, but actually applies to every cellular component. Once set in motion, the complex processes needed to generate cytoplasm of such quality may not be easily paused. Mature oocytes may be too large to store so that follicles are instead stored at an early stage, corresponding to the primordial follicle.

Drosophila may have evolved GSCs to adapt to an ecological niche in which food and oviposition sites are limited and only sporadically available. When an opportunity arises, the ability of a Drosophila female to lay many eggs rapidly is crucial for reproductive success. If very young follicles were stored, they would take three days to develop to maturity, too long to be of much help in a short-lived, competitive situation. Stem cells allow adult Drosophila to maintain a steady stream of follicles developing until vitellogenesis, just one day from maturity. Follicles at this stage do not appear to be storable; they either mature or undergo atresia and are recycled. The net effect of using stem cells and recycling follicles, is that Drosophila females maintain a constant supply of developing follicles that can be completed with minimal delay to produce bursts of high-quality female gametes during the sporadic instances when they are needed.

\section{THE DROSOPHILA TESTIS GERMLINE STEM CELL NICHE}

Germline stem cells are also maintained by local signals from a somatic support cell niche in Drosophila males, and there are many themes in common with female germline stem cells in the ovary. However, sex-specific differences in how and when similar signaling pathways and control mechanisms are employed, as well as differences in which aspects have been most deeply investigated in testes versus ovaries, have contributed to intriguing differences in the current picture of how these two anatomically related systems work. For example, the translational inhibitors NANOS and PUMILIO are not required for germline stem cell maintenance in males, suggesting that male germline stem cells may not be primed by expression of translationally silenced differentiation transcripts in the same way as are female GSCs. Likewise, although bam also acts as a differentiation factor in males, it normally functions at a different step in the germ cell lineage than in females. Onset of bam expression occurs after male germ cells have entered the TA division program and bam function is not needed to initiate the spermatogonial divisions. Rather, in males, bam is required for spermatogonia to cease mitosis and enter the meiotic program (Gönczy et al. 1997) and the timing and level of accumulation of bam protein controls the number of cyst divisions (Insco et al. 2009). Nevertheless, forced ectopic expression of bam in male GSCs can induce GSC differentiation (Sheng et al. 2009a), suggesting that bam has the capacity to block expression of factors required for GSC maintenance, even though it is not the key component that normally does so to initiate the male germ cell differentiation program.

Oriented Spindles and a Local Niche Program the Asymmetric Outcome of Stem Cell Divisions

Approximately 6-12 Drosophila male GSCs lie in a rosette around a tight cluster of largely somatic support cells called the hub, located at the apical tip of each testis. Drosophila male GSCs normally divide asymmetrically: the mitotic spindle is set up perpendicular to the hub-GSC interface so that, upon cytokinesis, one daughter remains next to the hub and maintains stem cell identity, whereas the other daughter is displaced away and initiates differentiation, becoming a gonialblast (Gb) (Fig. 2B). This arrangement of the GSCs around the hub is set up before the end of embryogenesis and male germ cells divide with oriented spindles and begin producing differentiating daughter cells by onset of the larval stages (Kiger et al. 2001; Le Bras and Van Doren 2006; Sheng et al. 2009b). Thus, formation of the niche and conversion from PGCs to GSCs occurs much earlier in males than in females.

As in females, GSCs in the testis physically attach to the hub by localized adherens junctions, which allow GSCs to hold on to and compete for position at the hub. Male germline 
stem cells made homozygous mutant for E-cad are lost to differentiation. E-cad localized in the adherens junctions provides binding sites for $\beta$-catenin and APC2, a homolog of the adenomatous polyposis coli tumor suppressor, concentrating them at the GSC cortex adjacent to the hub (Yamashita et al. 2003).

The adherens junctional complexes between GSCs and the hub provide polarity cues toward which GSCs orient their centrosomes throughout interphase and their spindle during mitosis cell (Yamashita et al. 2003; Inaba et al. 2010). In $\mathrm{G1}$, the single centrosome in each GSC retains a robust array of microtubules and localizes near the cell cortex where the germ cell attaches to the hub. The position of the centrosome may be set via direct or indirect interactions between the microtubules and APC2 protein localized at the adherens junction. This unusual centrosome behavior is characteristic of the GSCs but not of TA spermatogonia, and so appears to be part of the stem cell program. When the duplicated centrosomes separate, early in G2, one stays next to the hub while the other migrates to the opposite side of the cell. The stereotyped position of the centrosomes in turn orients the mitotic spindle perpendicular to the GSC-hub cell interface, ensuring the normally asymmetric outcome of GSC divisions: one daughter inherits the attachment to the hub, remains subject to local niche signals, and renews stem cell identity, whereas the other is displaced away from the niche and normally initiates differentiation (Yamashita et al. 2003, 2007; Yamashita and Fuller 2005). A checkpoint mechanism blocks progression into mitosis unless a centrosome is properly situated next to the attachment to the hub (Cheng et al. 2008), ensuring reliable spindle orientation and the programmed asymmetric outcome of stem cell divisions. Differential labeling of mother versus daughter centrosomes by transient expression of a green fluorescent protein (GFP)tagged centriolar protein fragment revealed that the two centrosomes in male GSCs have different characters and fates. The mother centrosome normally remains adjacent to the hub and is inherited by the GSC, while the daughter centrosome migrates to the opposite side of the cell and is inherited by the Gb. As a result, male GSCs maintain a centriolar Eve, assembled many cell generations earlier (Yamashita et al. 2007).

The Testis Maintains Two Stem Cell Types, Which Produce Progeny that Work Together

The GSCs attached to the hub are flanked by somatic cyst stem cells (CySCs) (Fig. 2B). The CySCs lie with their cell bodies displaced away from the hub but maintain contact with it via thin cytoplasmic processes that extend down between the GSCs to touch the hub. CySCs and GSCs appear to compete for binding to the hub, with adhesion regulated so that GSCs normally win (Issigonis et al. 2009; Sheng et al. 2009a,b). The cytoplasmic processes of the CySCs insulate the GSCs from each other. The CySCs also divide with spindles oriented perpendicular to the interface with the hub, although spindles in CySCs are usually first set up roughly parallel with the hub surface, then reorient during anaphase so that one pole is next to the hub (Cheng et al. 2011). When CySCs divide, the daughter that maintains attachment to the hub maintains stem cell identity and the daughter displaced away from the hub normally differentiates as a cyst cell. Two cyst cells interact with a Gb produced by a nearby dividing GSC to form the functional unit of differentiation, the germline cyst (Fig. $2 \mathrm{~B}$, right). The epidermal growth factor (EGF) class ligand Spitz secreted by the germ cell activates the EGFR on the cyst cells and through the guanine exchange factor Vav differentially activates the small GTPase Rac, causing the cyst cells to send out processes and envelop the Gb (Sarkar et al. 2007). The cyst cells normally do not divide again, but accompany and codifferentiate with the germ cells they enclose throughout the process of spermatogenesis (Gönczy et al. 1992; Voog et al. 2008). In this way, the cyst cells functionally resemble Sertoli cells in mammalian testes, although individual cyst cells do not associate with germ cells at different stages. The maintenance of two stem cell types attached to the same apical hub may be an anatomical mechanism to facilitate production of 
A. Spradling et al.

daughter cells that must work together for proper differentiation.

Once enclosed by the cyst cells, the Gb embarks on the spermatogonial mitotic divisions. As in mammals, the TA spermatogonia within a cyst divide in metasynchrony and undergo incomplete cytokinesis, retaining cytoplasmic bridges that develop into ring canals (see Greenbaum et al. 2011). The number of spermatogonial divisions varies with Drosophila species but is four in D. melanogaster. After the fourth spermatogonial division, the 16 sister germ cells within the cyst together enter premeiotic DNA synthesis (see Kimble 2011) then initiate the spermatocyte program, which includes cell growth and a cell type specific gene expression program that prepares for the dramatic cell morphogenesis that follows the meiotic divisions (see White-Cooper and Davidson 2011). It is intriguing that the 16-cell stage is also an important regulatory point in the spermatogonial division program in mammals.

\section{TA Cells Can Revert to the Stem Cell State to Replace Lost GSCs}

Although TA spermatogonia are clearly differentiating and can be distinguished from stem cells based on cell division behavior, subcellular structures, and gene expression patterns, early spermatogonia are not yet committed to differentiation. Indeed, TA spermatogonia can break apart from germ cell cysts, reoccupy the niche, and revert to stem cell behavior. Male germ cells induced to begin differentiation due to temporary down-regulation of STAT activity or temporary forced early expression of bam will return to the niche and resume stem cell behavior once the abnormal genetic condition is reversed, as long as the spermatogonia have not advanced too far toward becoming spermatocytes (Brawley and Matunis 2004; Sheng et al. 2009a). Genetic marking experiments demonstrated that TA spermatogonia that have advanced to the four-cell cyst stage and turned on bam expression can, and indeed frequently do, return to the hub and resume stem cell identity and behavior, even in the absence of drastic genetic perturbations (Cheng et al. 2008). If
GSCs at the hub are killed by irradiation, stem cells are replaced by massive dedifferentiation of TA spermatogonia. Drosophila female germ cells exhibit similar behavior: Germ cells induced to enter the cystocyte mitotic divisions by a pulse of forced expression of bam can revert back to the stem cell state (Kai and Spradling 2004). Dedifferentiation of TA cells may be an important mechanism to replace lost stem cells in situations where stem cells normally divide with a strictly programmed oriented spindle. As discussed below, replacement of stem cells by dedifferentiation of TA cells also appears to occur during mammalian spermatogenesis (Nakagawa et al. 2010). This ability means that transplantation assays may detect not only the most fundamental stem cells, but also possibly early TA cells that have initiated but are not yet committed to differentiation. The ability of TA germ cells to revert to the stem cell state may reflect an underlying regulatory logic where the decision to proceed from mitosis into meiosis is taken gradually (see Kimble 2011).

Cell-Cell Interactions Maintain Germline and Somatic Stem Cells in the Testis Stem Cell Niche

The niche for male GSCs in Drosophila is complex, involving contributions from two somatic cell types, the hub and the CySCs. A cytokinelike signaling system maintains both the GSCs and the CySCs. The somatic cells of the apical hub express the secreted ligand Upd, which binds the receptor, Domeless, activating the single Drosophila JAK, encoded by the hopscotch gene. The activated JAK then phosphorylates the transcription factor STAT in the cytoplasm, causing it to dimerize, move into the nucleus, and bind to target DNA sequences.

Action of STAT is required cell autonomously in male GSCs to maintain attachment of GSCs to the hub. Individual GSCs made homozygous mutant for STAT by recombination in a STAT / + background are lost to differentiation (Kiger et al. 2001; Tulina and Matunis 2001). Genetic manipulations that cause loss of STAT function in all germ cells while 
preserving STAT function in the somatic CySC lineage result in detachment of GSCs from the hub, with CySCs moving in to fill the vacated space (Leatherman and Dinardo 2010). Strikingly, however, action of STAT within germ cells appeared neither necessary nor sufficient to maintain germ cells in the stem cell state. The germ cells displaced from the hub after loss of STAT function in germline but not in somatic cells maintained stem cell characteristics, in that they were able to produce differentiating male germ cells and support spermatogenesis for weeks (Leatherman and Dinardo 2010). Conversely, forced expression of constitutively active JAK in early male germ cells did not cause overproliferation of GSC-like cells (Leatherman and Dinardo 2008). Thus a major role of activation of STAT in GSCs by the Upd signal from the hub appears to be maintaining attachment to the hub rather than specifying stem cell selfrenewal. Instead, as we shall see below, maintenance of attachment to the hub serves to hold GSCs in a privileged microenvironment provided by the somatic CySCs, whereas centrosome orientation toward the attachment site sets up an oriented spindle and programs the normally asymmetric outcome of GSC divisions (Fig. 2B).

Activation of STAT in CySCs appears to be both necessary and sufficient to maintain the somatic cells in the stem cell state (Leatherman and Dinardo 2008). CySCs made homozygous mutant for STAT in somatic cell clones failed to self-renew and were quickly lost from the tip of the testis. Tellingly, forced expression of constitutively active JAK in the somatic cyst cell lineage resulted in overproliferation of CySC-like cells. The activation of STAT in CySC is likely to specify maintenance of the stem cell state through action of the transcriptional repressors ZFH1 and CHINMO (Leatherman and Dinardo 2008; Flaherty et al. 2010). Both ZFH1 and CHINMO are expressed in CySCs and present in decreasing levels in their cyst cell progeny. Clonal analysis revealed that loss of function of either, results in loss of CySCs. Conversely, forced expression of high levels of either ZFH1 or CHINMO resulted in continued proliferation of the somatic cells, even away from the hub, and failure to turn on the cyst cell differentiation marker Eya, suggesting that either ZFH1 or CHINMO are sufficient to maintain CySCs in a stem cell-like state (Leatherman and Dinardo 2008; Flaherty et al. 2010). Strikingly, when CySCs were maintained in a stem cell-like state by forced expression of ZFH1, CHINMO, or constitutively active JAK in the cyst cell lineage, neighboring germ cells continued to proliferate in a stem cell or Gb-like state and rarely turned on expression of TA stage differentiation markers such as bam (Leatherman and Dinardo 2008; Flaherty et al. 2010).

A new picture of a complex niche governing GSC self-renewal and differentiation in the Drosophila testis is emerging from these recent findings (Fig. 2B). In this model, Upd signals from the hub instruct neighboring CySCs to maintain stem cell identity. The CySCs in turn provide a privileged microenvironment that maintains neighboring germ cells in a stem cell state. Meanwhile, activation of STAT in germ cells in response to the Upd signal from the hub instructs GSCs to remain attached to the hub, ensuring that they remain in the niche provided by the CySCs. Forced ectopic expression of Upd in GSCs maintains neighboring somatic cells in a proliferative CySC-like state, providing an expanded microenvironment for self-renewal of GSCs, resulting in a tumorlike mass of CySCs and GSCs. The current model is that CySCs send signal(s) that instruct GSCs to self-renew (Leatherman and Dinardo 2010) (lightning bolt in Fig. 2B). As in the ovary, transforming growth factor- $\beta$ (TGF- $\beta$ ) signaling is a likely candidate, as the TGF- $\beta$ class ligand $\mathrm{Gbb}$, expressed in somatic cells including early cyst cells at the tip of the testis, is required for GSC maintenance (Shivdasani and Ingham 2003). In addition, loss of function of TGF- $\beta$ pathway receptors or signal transduction components in GSCs causes loss of GSCs to differentiation. However, it remains to be determined whether TGF- $\beta$ signaling is permissive for GSC self-renewal, possibly by repressing expression of bam, or whether it plays an instructive role in maintaining the GSC state in males.

The lesson emerging from analysis of the C. elegans gonad and the Drosophila testis 
A. Spradling et al.

and ovarian systems is that decisions between self-renewal and differentiation of GSCs are regulated by local signals from nearby somatic support cells.

\section{THE MAMMALIAN TESTIS STEM CELL NICHE}

It is safe to say that relative to Drosophila, we know relatively little about the regulation of mammalian GSCs and the niche in which they reside. Unlike in Drosophila, there does not appear to be such a strictly defined anatomical niche, and it is near certain that a structure analogous to the hub does not exist in mammals, at least in rodents and primates (including man). There is no known equivalent of the hub or the CySC (see above). Nonetheless, GSCs seem to have a tendency to reside in certain regions of the seminiferous epithelium-near areas of the interstitium that contain branching blood vessels, and GSC behavior is clearly influenced by factors secreted by adjacent somatic Sertoli cells and interstitial peritubular myoid and Leydig cells.

In the mouse, where GSCs have been best studied, it is still not currently possible to definitely identify a specific cell as being a GSC. Instead, the current state of the field refers to a group of cells as representing the GSC compartment, comprised of germ cells with different extents of stem cell potential. This may reflect the ability of early spermatogonia to dedifferentiate (discussed below) and a gradual transition from stem cell to TA state, as proposed for C. elegans (see Kimble 2011).

Within the GSC compartment there are many similarities between mice and Drosophila. At the top of the existing hierarchy is the morphologically most primitive cell, the type A single $\left(A_{s}\right)$ spermatogonia (Fig. 1C). The $A_{s}$ cell can divide to form two new $A_{s}$ cells, or divide with incomplete cytokinesis to form a pair $\left(A_{p r}\right)$ of cells connected by an intercellular bridge. Those $A_{s}$ cells that produce an $A_{p r}$ may be the mammalian equivalent of the $\mathrm{Gb}$ in the Drosophila hierarchy. $\mathrm{A}_{\mathrm{pr}}$ cells divide to form a chain of four aligned cells $\left(\mathrm{A}_{\mathrm{al}-4}\right)$, which can divide to form large chains of $8\left(\mathrm{~A}_{\mathrm{al}-8}\right), 16$ $\left(\mathrm{A}_{\mathrm{al}-16}\right)$, and sometimes even $32\left(\mathrm{~A}_{\mathrm{al}-32}\right)$ cells before relinquishing the stem cell activity. Although not exactly analogous, the $A_{p r}$ and $\mathrm{A}_{\mathrm{al}}$ spermatogonial cysts are very much like the Drosophila TA cells (see above). As in Drosophila, the mitotic sisters remain connected by cystoplasmic bridges and divide in synchrony. All of these cell types have been shown experimentally to have the capacity to behave like GSCs, in that after transplantation they can form colonies that repopulate a recipient testis with both GSCs and differentiated cells (Nakagawa et al. 2007). However, the greatest selfrenewing potential likely resides within the $A_{s}$ population, and self-renewing potential falls as cyst length increases (see below). In contrast to D. melanogaster, where male and female germ cells normally enter meiosis at the 16-cell cyst stage, in mice different lengths of $\mathrm{A}_{\mathrm{al}}$ spermatogonial cysts transit into differentiating spermatogonia. Although cysts of 8 and 16 cells are the major population that undergo the switch, shorter cysts and even $\mathrm{A}_{\mathrm{s}}$ cells also transform into differentiating spermatogonia (Nakagawa et al. 2010).

A key regulatory point in mammalian spermatogenesis is the switch from early TA spermatogonia to differentiating spermatogonial cysts (Oakberg 1956). At a specific time during the $8.6 \mathrm{~d}$ cycle of the murine seminiferous epithelial cycle, cohorts of $A_{p r}$ and $A_{a l}$ spermatogonia differentiate into $A_{1}$ spermatogonia, which in turn divide to become $A_{2}, A_{3}, A_{4}$, intermediate (In), and eventually type $B$ spermatogonia, the penultimate cell type to the preleptotene spermatocyte (Fig. 1C). The older literature tends to favor nomenclature that refers to the $A_{s}$, $A_{p r}$, and $A_{a l}$ spermatogonia as undifferentiated spermatogonia, and the $A_{1-4}$, In, and $B$ spermatogonia as differentiated spermatogonia. Reasons for this include differences in cell cycle regulation (asynchronous division between different cysts of $A_{\text {pr }}$ and $A_{a 14-16}$ cells compared to relatively synchronous division of unrelated $A_{1}$ cysts, $A_{2}$ cysts, etc.) and chromatin structure. Even though there are differences between these two groups $\left(A_{s}, A_{p r}\right.$ and $A_{a l}$ compared to $A_{1-4}$, In, and $B$ ) of spermatogonia, we prefer not to use this nomenclature because the cytoplasmic bridges connecting $\mathrm{A}_{\mathrm{pr}}$ and larger cysts are an 
aspect of their differentiation, stem cell potential likely falls as cyst length increases within the $\mathrm{A}_{\mathrm{s}}, \mathrm{A}_{\mathrm{pr}}$ and $\mathrm{A}_{\mathrm{al}}$ populations, and, as in Drosophila, spermatogonia within developing cysts (usually referred to as chains in mammals) can separate from a cyst and revert to GSCs (Hogarth and Griswold 2010).

When cells enter meiosis in mammals is a bit of a semantic argument. To the meiotic scientist, meiosis begins when preleptotene spermatocytes undergo premeiotic DNA synthesis or when double-strand breaks are initiated and chromosomes pair. Germ cells appear to commit to progress toward meiotic entry at the $A_{a l}$ to $A_{1}$ transition, a critical juncture that is under retinoic acid regulation, but only initiate meiosis after six more mitotic cell divisions.

Embryonic Induction of Primordial Germ Cells and Their Differentiation into GSCs

PGCs in mammals are an induced cell lineage that arise extragonadally around the onset of gastrulation at embryonic day E7.25 (Ginsburg et al. 1990; Lawson and Hage 1994). Embryonic position and extracellular signaling molecules, including BMP4 and BMP8b, are required for PGC formation (Lawson et al. 1999; Ying et al. 2000). Critical to becoming a PGC is the need to avoid differentiating (Seydoux and Braun 2006). Both chromatin modifying enzymes (BLIMP1/PRDM1 and PRDM14) and regulators of miRNA function (LIN28) play essential roles in PGC formation and retention of a permissive epigenetic state (Ohinata et al. 2005; Vincent et al. 2005; Yamaji et al. 2008; West et al. 2009). Perhaps not coincidentally, segregation of PGCs from embryonic signaling cues bestows on them retention of pluripotency and the ability to form teratomas (Stevens 1967). PGCs retain the ability to form teratomas until their migration into the genital ridge and until testicular cord formation in males.

The molecular mechanisms governing the transition from a PGC to a GSC are not known. However, it is likely that it happens gradually during fetal development, is influenced by signaling from somatic cells of the gonad, and does not involve all of the PGCs. Conditional ablation in fetal Sertoli cells of SIN3A, a component of a large transcriptional remodeling complex, results in down-regulation of several germ cell-expressed pluripotency and GSC genes (e.g., Oct3/4, Gfra1, c-Ret, promyelocytic leukemia zinc finger $[\mathrm{PLZF}])$ and greatly reduces teratoma formation when fetal gonads are transferred to an ectopic site (Payne et al. 2010). Ablation of SIN3A in Sertoli cells does not lead to loss in the absolute numbers of fetal germ cells, suggesting that SIN3A-mediated signaling from fetal Sertoli cells is specifically required to retain pluripotency in germ cells. The CXCl12 ligand, which is expressed in Sertoli cells, and its receptor CXCR4, which is expressed in germ fetal germ cells, may be important mediators of SIN3A activity (Payne et al. 2010). The CXCL12/CXCR4 signaling system is also required for guidance of PGC migration and survival, and both are up-regulated in germ cell tumors in patients (Doitsidou et al. 2002; Molyneaux et al. 2003; Gilbert et al. 2009).

\section{Properties of Postnatal GSCs}

The early postnatal gonad in mice contains a heterogeneous group of germ cells in regard to both gene expression and function. The onset of postnatal germ cell proliferation and the chronology of the formation of the first mature sperm have long supported the belief that the first wave of spermatogenesis is different from steady-state spermatogenesis in adults (de Rooij 1998). Lineage tracing experiments have confirmed this notion and have demonstrated that the first sperm originate from a subset of postnatal germ cells that are the equivalent of $A_{1}$ (Yoshida et al. 2006). GSCs are derived from the remaining population of perinatal germ cells. During prepubertal growth, Sertoli cells proliferate, presumptive GSCs migrate from their perinatal embryonic luminal position to the basal lamina, and a functional niche is established to maintain self-renewal of GSCs and steady-state spermatogenesis.

Genetic studies suggest that both transcriptional and translational regulation is important for murine GSC self-renewal. Mutations in the gene encoding PLZF transcription factor result 
A. Spradling et al.

in an age-dependent loss of GSCs (Buaas et al. 2004; Costoya et al. 2004). Several other transcription factors (e.g., TAF4b, BCL6b, ETV5, and LHX1) have also been implicated in GSC self-renewal (Chen et al. 2005; Falender et al. 2005; Oatley et al. 2006). In most cases, the genes downstream from these transcription factors have not yet been identified. Less is known about the importance of translational control, but NANOS2, whose expression is highly restricted to $A_{s}, A_{p r}$ and short chains of $A_{a l}$ spermatogonia, is also required for GSC self-renewal (Sada et al. 2009). The requirement for LIN28 for PGC formation, and its expression in the GSC compartment, suggests that the let7 class of miRNAs may also function in GSCs (West et al. 2009).

As described below, glial cell-derived neurotrophic factor (GDNF) expression from Sertoli cells is critical for GSC self-renewal. GDNF interacts with GSCs via direct binding to its receptor GFR $\alpha 1$ and its coreceptor, c-Ret. Like all genes known to be expressed in the GSC compartment, GFR $\alpha 1$ expression is heterogeneous, and it tends to be expressed in most $A_{s}$, $A_{p r}$ and small chains of $A_{a l}$ spermatogonia and be absent in longer chains of $\mathrm{A}_{\mathrm{al}}$ spermatogonia. Several signaling pathways have been suggested to function downstream from GFR $\alpha 1 / c-R e t$ in GSCs. These include the Src family kinases and the PI3-kinase-AKT pathways (Braydich-Stolle et al. 2007; Lee et al. 2007). Recent studies have suggested that mTORC1 antagonizes GFR $\alpha 1 / c-$ Ret signaling, which decreases PI3K/AKT signaling, resulting in a shift in balance toward GSC differentiation (Hobbs et al. 2010). mTORC1 levels are thought to be negatively regulated by REDD1, whose expression is under positive regulation by PLZF. In this model, loss of PLZF leads to an elevation of mTORC1 activity, increased inhibition of GFR $\alpha 1 / c-$ Ret signaling, and loss of GSC selfrenewal.

Regulatory Interactions between GSCs and Their Environment

Seminiferous tubules are composed of germ cells and somatic Sertoli cells (Fig. 2B). The tubules are surrounded by a specialized extracellular matrix, the basal lamina, which in turn is wrapped with specialized peritubular myoid cells. In the interstitial space between tubules lie the steroidogenic Leydig cells, the vasculature, immune cells, and rare fibroblastlike cells. Within the tubules, extensive tight junctions between Sertoli cells create two compartments: a basal compartment demarcated by the basal lamina at the tubule circumference and an adluminal compartment that extends to the lumen of the tubule. The basal compartment segregates the spermatogonia from the more differentiated meiotic and postmeiotic germ cells. All spermatogonia $\left(A_{s}, A_{p r}, A_{a l}\right.$, A1-4, In, and B types) occupy the basal compartment, lie along the basal lamina of the epithelium, and are in direct contact with somatic Sertoli cells. In addition, $A_{s}, A_{p r}, A_{a l}$, and more differentiated spermatogonia are intermingled with each other in the basal compartment. The basal compartment repeats the same simple structure around the circumference and along the length of seminiferous tubules. Upon differentiation into preleptotene spermatocytes the cells permanently lose contact with the basal lamina and move from the basal to the adluminal compartment of the epithelium.

Although GSCs can be found along the length of the entire seminiferous epithelium, GSCs appear to preferentially locate in regions of the epithelium in greatest contact with the interstitium, rather than juxtaposed to another tubule, and in areas that contain branching vasculature (Chiarini-Garcia et al. 2001; Yoshida et al. 2007). E-cad is expressed on GSCs in mice, suggesting adherence junctions may be important for GSC behavior. However, despite the important role of E-cad-mediated binding of GSCs to the hub in asymmetric division and self-renewal in Drosophila (see above), genetic ablation of E-cad in cultured mouse GSCs does not affect their ability to repopulate and establish normal spermatogenesis in transplantation studies (Kanatsu-Shinohara et al. 2008).

An important feature of murine GSCs in mice is their motility. Live imaging of EGFPlabeled $A_{s}, A_{p r}$ and $A_{a l}$ cells clearly demonstrates extensive migration along the $X / Y$ axis 
of the basal lamina (Yoshida et al. 2007). Therefore, unlike in Drosophila, where GSCs are bound to the hub, murine GSCs can disperse themselves along the surface of the epithelium. This may be an important adaptation of mammalian GSCs to the different anatomical design of the insect versus the mammalian testis and may explain why there does not appear to be an anatomical stem cell niche in mammals. In Drosophila, the testis is essentially one-dimensional-GSCs reside at one end of the tubular structure and differentiate as they move down the tubule. In mammals, the seminiferous epithelium is functionally three dimensionalGSCs lie along the entire circumference of the tubule and translocate along the $Z$ axis toward the lumen as they differentiate. Homeostasis of the mammalian seminiferous epithelium requires coordination of the initiation of spermatogenesis both spatially and temporally. The apparent stochastic nature of self-renewal within the GSC compartment (discussed below), requires that GSCs be motile so that they are able to respond to changes in germ cell density and relocate along the length of the tubule during both steady-state and regenerative spermatogenesis.

Sertoli cells interact with all germ cells within the epithelium and clearly play both instructive and permissive roles in spermatogenesis (refer to Matzuk et al. 2011). The development of an in vitro culture system for murine GSCs has allowed rapid screening for growth factors that promote survival or proliferation in vitro. Stem cell properties can be assayed in cultured cells (e.g., expression of Oct3/4, GFR $\alpha 1$, or PLZF) or in functional transplantation experiments. Several growth factors, including IGF-1 and FGF2 (also known as bFGF) have been implicated in survival or expansion of GSCs in culture (Kanatsu-Shinohara et al. 2003; Kubota et al. 2004). CSF-1, which is expressed in peritubular myoid cells and Leydig cells, and promotes GSC selfrenewal in vitro (Oatley et al. 2009), may be an important extrinsic regulator of self-renewal.

Both genetic and in vitro studies unequivocally support a major role for Sertoli cell expression of GDNF in GSC maintenance. Loss of
GDNF signaling in vivo results in age-dependent depletion of the GSC compartment (Meng et al. 2000) and overexpression of GDNF leads to expansion of the GSC compartment (Meng et al. 2000; Creemers et al. 2002; Yomogida et al. 2003). In vitro studies with GSC cultures suggest that GDNF may promote the selfrenewal of GSCs by stimulating their survival or proliferation (Tadokoro et al. 2002; KanatsuShinohara et al. 2003; Kubota et al. 2004). Not yet known is whether the local concentration of GDNF protein varies locally along the seminiferous epithelium both spatially and temporally and how self-renewal signaling from GDNF is balanced with signaling that must be required for differentiation.

Heterogeneity of GSC Potential within the GSC Compartment

A long-held presumption in mice has been that the $A_{s}$ spermatogonia are the stem cells, whereas $A_{p r}$ and $A_{a l}$ spermatogonia are irreversibly committed to differentiation (Huckins 1971; Oakberg 1971; de Rooij 1973). Support for this model stemmed from the fact that the $A_{s}$ cells are the most primitive spermatogonia, they are not connected to other cells through intercellular bridges, they have a large nuclearto-cytoplasmic ratio, and they are present in all stages of the seminiferous cycle. Three lines of evidence suggest that this long-held assumption is incorrect. First, all of these cell types have been shown experimentally to have the capacity to behave like GSCs, in that after transplantation they can form colonies that repopulate a recipient testis with both GSCs and differentiated cells (Nakagawa et al. 2010). It is likely, although not yet formally proven, that the greatest self-renewing potential resides within the $A_{s}$ population, and self-renewing potential falls as cyst length increases. Second, genes that are required cell autonomously in GSCs for self-renewal, for example, Gfra1, Plzf, and Nanos2, are not limited in their expression to $A_{s}$ cells. Every marker analyzed to date, whether present in stem cell-enriched populations used for transplantation or detected by immunostaining in whole-mount tubules, 
A. Spradling et al.

shows variable expression within the $A_{s}, A_{p r}$ and $A_{a l}$ population; this includes $G F R \alpha 1$, NGN3, NANOS2, E-cad, and PLZF (Buaas et al. 2004; Yoshida et al. 2004; Suzuki et al. 2009; Nakagawa et al. 2010). All of these markers are expressed in some, but not all $A_{s}$, $A_{p r}$ and $A_{a l}$ cells. This heterogeneity in gene expression suggests an unstable epigenetic state reflecting both self-renewal and differentiating properties within the pool of cells. Lastly, live imaging and lineage tracing during steady-state spermatogenesis have shown that, as in Drosophila, interconnected spermatogonia in a TA cyst occasionally fragment into single spermatogonia or shorter cysts (Nakagawa et al. 2010).

The ability of TA germ cells to revert to the stem cell state may reflect an underlying regulatory logic where the decision to proceed from mitosis into meiosis is taken gradually (see Kimble 2011). This characteristic, observed in animal species as disparate as flies and mice, may help ensure the persistence of gametogenesis, especially for animals with long reproduction periods.

\section{Do Mouse GSCs Undergo Asymmetric Cell Division?}

A prevailing idea is that stem cells are located in specialized anatomical niches and that asymmetric cell division produces one self-renewing daughter that remains in the niche and another daughter that leaves the niche and differentiates. However, mathematical analyses of single stem cell-derived cohorts in mouse testes indicate that stem cells that are located sparsely with respect to each other do not remain tethered to particular positions, and that GSCs replace each other at a surprisingly high frequency (Klein 2010). In support of this, detailed live in vivo imaging clearly demonstrates migration, expansion, and replacement of $A_{s}, A_{p r}$ and $A_{a l}$ within 8.6 days (i.e., one cycle of the seminiferous epithelium) (Yoshida et al. 2007; Klein et al. 2010). Moreover, this replacement is, as a whole, revealed to be a random event. In addition, the breakdown of TA spermatogonial cysts to generate new GSCs need not be regulated, and instead, may also be a stochastic event (Klein et al. 2010; Nakagawa et al. 2010). These findings are not easily explained by the prevailing deterministic asymmetric model and suggest a stochastic model of self-renewal and differentiation. However, it remains a formal possibility, as observed in the Drosophila testis, that the localized niche microenvironment that allows or instructs GSC self-renewal, influences the divisions oriented with respect to this niche so that one daughter usually remains in the niche and the other is usually displaced away.

\section{REFERENCES}

Angelo G, Van Gilst MR. 2009. Starvation protects germline stem cells and extends reproductive longevity in C. elegans. Science 326: 954-958.

Austin J, Kimble J. 1987. glp-1 is required in the germline for regulation of the decision between mitosis and meiosis in C. elegans. Cell 51: 589-599.

Brawley C, Matunis E. 2004. Regeneration of male germline stem cells by spermatogonial dedifferentiation in vivo. Science 304: 1331-1334.

Braydich-Stolle L, Kostereva N, Dym M, Hofmann MC. 2007. Role of Src family kinases and N-Myc in spermatogonial stem cell proliferation. Dev Biol 304: 34-45.

Buaas FW, Kirsh AL, Sharma M, McLean DJ, Morris JL, Griswold MD, de Rooij DG, Braun RE. 2004. Plzf is required in adult male germ cells for stem cell selfrenewal. Nat Genet 36: 647-652.

Büning T, Spradling AC. 2007. The insect ovary: Ultrastructure, previtellagenic growth and evolution. Chapman and Hall, London.

Casanueva MO, Ferguson EL. 2004. Germline stem cell number in the Drosophila ovary is regulated by redundant mechanisms that control Dpp signaling. Development 131: $1881-1890$.

Chau J, Kulnane LS, Salz HK. 2009. Sex-lethal facilitates the transition from germline stem cell to committed daughter cell in the Drosophila ovary. Genetics 182: $121-132$.

Chen D, McKearin D. 2003. Dpp signaling silences bam transcription directly to establish asymmetric divisions of germline stem cells. Curr Biol 13: 1786-1791.

Chen C, Ouyang W, Grigura V, Zhou Q, Carnes K, Lim H, Zhao GQ, Arber S, Kurpios N, Murphy TL, et al. 2005 ERM is required for transcriptional control of the spermatogonial stem cell niche. Nature 436: 1030-1034.

Cheng J, Turkel N, Hemati N, Fuller MT, Hunt AJ, Yamashita YM. 2008. Centrosome misorientation reduces stem cell division during ageing. Nature 456: 599-604.

Cheng J, Tiyaboonchai A, Yamashita YM, Hunt AJ. 2011. Asymmetric division of cyst stem cells in Drosophila testis is ensured by anaphase spindle repositioning. Development 138: $831-837$.

Chiarini-Garcia H, Hornick JR, Griswold MD, Russell LD. 2001. Distribution of type A spermatogonia in the mouse is not random. Biol Reprod 65: 1179-1185. 
Cinquin O, Crittenden SL, Morgan DE, Kimble J. 2010. Progression from a stem cell-like state to early differentiation in the C. elegans germ line. Proc Natl Acad Sci 107: 2048-2053.

Civetta A, Rajakumar SA, Brouwers B, Bacik JP. 2006. Rapid evolution and gene-specific patterns of selection for three genes of spermatogenesis in Drosophila. Mol Biol Evol 23: 655-662.

Costoya JA, Hobbs RM, Barna M, Cattoretti G, Manova K, Sukhwani M, Orwig KE, Wolgemuth DJ, Pandolfi PP. 2004. Essential role of Plzf in maintenance of spermatogonial stem cells. Nat Genet 36: 653-659.

Creemers LB, Meng X, den Ouden K, van Pelt AM, Izadyar F, Santoro M, Sariola H, de Rooij DG. 2002. Transplantation of germ cells from glial cell line-derived neurotrophic factor-overexpressing mice to host testes depleted of endogenous spermatogenesis by fractionated irradiation. Biol Reprod 66: 1579-1584.

Davies EL, Fuller MT. 2008. Regulation of self-renewal and differentiation in adult stem cell lineages: Lessons from the Drosophila male germ line. CSHSQB 73: 137-145.

Decotto E, Spradling AC. 2005. The Drosophila ovarian and testis stem cell niches: Similar somatic stem cells and signals. Dev Cell 9: 501-510.

Deng W, Lin H. 1997. Spectrosomes and fusomes anchor mitotic spindles during asymmetric germ cell divisions and facilitate the formation of a polarized microtubule array for oocyte specification in Drosophila. Dev Biol 189: 79-94.

de Rooij DG. 1973. Spermatogonial stem cell renewal in the mouse. I. Normal situation. Cell Tissue Kinet 6: 281-287.

de Rooij DG. 1998. Stem cells in the testis. Int J Exp Pathol 79: $767-780$.

Doitsidou M, Reichman-Fried M, Stebler J, Koprunner M, Dorries J, Meyer D, Esguerra CV, Leung T, Raz E. 2002. Guidance of primordial germ cell migration by the chemokine SDF-1. Cell 111: 647-659.

Draper BW, McCallum CM, Moens CB. 2007. Nanos1 is required to maintain oocyte production in adult zebrafish. Dev Biol 305: 589-598.

Drummond-Barbosa D. 2008. Stem cells, their niches and the systemic environment: An aging network. Genetics 180: $1787-1797$.

Falender AE, Freiman RN, Geles KG, Lo KC, Hwang K, Lamb DJ, Morris PL, Tjian R, Richards JS. 2005. Maintenance of spermatogenesis requires TAF $4 \mathrm{~b}$, a gonadspecific subunit of TFIID. Genes Dev 19: 794-803.

Fichelson P, Moch C, Ivanovitch K, Martin C, Sidor CM, Lepesant JA, Bellaiche Y, Huynh JR. 2009. Live-imaging of single stem cells within their niche reveals that a U3snoRNP component segregates asymmetrically and is required for self-renewal in Drosophila. Nat Cell Biol 11: 685-693.

Flaherty MS, Salis P, Evans CJ, Ekas LA, Marouf A, Zavadil J, Banerjee U, Bach EA. 2010. Chinmo is a functional effector of the JAK/STAT pathway that regulates eye development, tumor formation, and stem cell self-renewal in Drosophila. Dev Cell 18: 556-568.

Flatt T, Min KJ, D’Alterio C, Villa-Cuesta E, Cumbers J, Lehmann R, Jones DL, Tatar M. 2008. Drosophila germ-line modulation of insulin signaling and lifespan. Proc Natl Acad Sci 105: 6368-6373.

Forbes A, Lehmann R. 1998. Nanos and Pumilio have critical roles in the development and function of Drosophila germline stem cells. Development 125: 679-690.

Forstemann K, Tomari Y, Du T, Vagin VV, Denli AM, Bratu DP, Klattenhoff C, Theurkauf WE, Zamore PD. 2005. Normal microRNA maturation and germ-line stem cell maintenance requires Loquacious, a double-stranded RNA-binding domain protein. PLoS Biol 3: e236. 10.1371/journal.pbio.0030236.

Fuller MT, Spradling AC. 2007. Male and female Drosophila germline stem cells: Two versions of immortality. Science 316: 402-404.

Gilbert DC, Chandler I, McIntyre A, Goddard NC, Gabe R, Huddart RA, Shipley J. 2009. Clinical and biological significance of CXCL12 and CXCR4 expression in adult testes and germ cell tumours of adults and adolescents. J Pathol 217: 94-102.

Gilboa L, Lehmann R. 2004. Repression of primordial germ cell differentiation parallels germ line stem cell maintenance. Curr Biol 14: 981-986.

Gilboa L, Lehmann R. 2006. Soma-germline interactions coordinate homeostasis and growth in the Drosophila gonad. Nature 443: 97-100.

Ginsburg M, Snow MH, McLaren A. 1990. Primordial germ cells in the mouse embryo during gastrulation. Development 110: 521-528.

Gönczy P, Viswanathan S, DiNardo S. 1992. Probing spermatogenesis in Drosophila with P-element enhancer detectors. Development 114: 89-98.

Gönczy P, Matunis E, DiNardo S. 1997. Bag-of-marbles and benign gonial cell neoplasm act in the germline to restrict proliferation during Drosophila spermatogenesis. Development 124: 4361-4371.

Greenbaum M, Iwamori T, Buchold G, Matzuk MM. 2011. Germ cell intercellular bridges. Cold Spring Harb Perspect Biol doi:10.1101/cshperspect.a005850.

Guo Z, Wang Z. 2009. The glypican Dally is required in the niche for the maintenance of germline stem cells and short-range BMP signaling in the Drosophila ovary. Development 136: 3627-3635.

Hatfield SD, Shcherbata HR, Fischer KA, Nakahara K, Carthew RW, Ruohola-Baker H. 2005. Stem cell division is regulated by the microRNA pathway. Nature 435: 974-978.

Hayashi Y, Kobayashi S, Nakato H. 2009. Drosophila glypicans regulate the germline stem cell niche. J Cell Biol 187: $473-480$.

Hobbs RM, Seandel M, Falciatori I, Rafii S, Pandolfi PP. 2010. Plzf regulates germline progenitor self-renewal by opposing mTORC1. Cell 142: 468-479.

Hogarth CA, Griswold MD. 2010. The key role of vitamin A in spermatogenesis. J Clin Invest 120: 956-962.

Hsu HJ, Drummond-Barbosa D. 2009. Insulin levels control female germline stem cell maintenance via the niche in Drosophila. Proc Natl Acad Sci 106: 1117-1121.

Hsu HJ, LaFever L, Drummond-Barbosa D. 2008. Diet controls normal and tumorous germline stem cells via insulin-dependent and -independent mechanisms in Drosophila. Dev Biol 313: 700-712. 
A. Spradling et al.

Huckins C. 1971. The spermatogonial stem cell population in adult rats. I. Their morphology, proliferation and maturation. Anat Rec 169: 533-557.

Inaba M, Yuan H, Salzmann V, Fuller MT, Yamashita YM. 2010. E-cadherin is required for centrosome and spindle orientation in Drosophila male germline stem cells. PLoS One 5: e12473. 10.1371/journal.pone.0012473.

Insco M, Leon A, Tam C, McKearin D, Fuller MT. 2009 Accumulation of a differentiation regulator specifies transit amplifying division number in an adult stem cell lineage. Proc Natl Acad Sci 106: 22311-22316.

Iovino N, Pane A, Gaul U. 2009. miR-184 has multiple roles in Drosophila female germline development. Dev Cell 17: $123-133$.

Issigonis M, Tulina N, de Cuevas M, Brawley C, Sandler L, Matunis E. 2009. JAK-STAT signal inhibition regulates competition in the Drosophila testis stem cell niche. Science 326: 153-156.

Jin Z, Xie T. 2007. Dcr-1 maintains Drosophila ovarian stem cells. Curr Biol 17: 539-544.

Jin Z, Kirilly D, Weng C, Kawase E, Song X, Smith S, Schwartz J, Xie T. 2008. Differentiation-defective stem cells outcompete normal stem cells for niche occupancy in the Drosophila ovary. Cell Stem Cell 2: 39-49.

Johnston LA. 2009. Competitive interactions between cells: Death, growth, and geography. Science 324: 1679-1682.

Kai T, Spradling A. 2004. Differentiating germ cells can revert into functional stem cells in Drosophila melanogaster ovaries. Nature 428: 564-569.

Kanatsu-Shinohara M, Ogonuki N, Inoue K, Miki H, Ogura A, Toyokuni S, Shinohara T. 2003. Long-term proliferation in culture and germline transmission of mouse male germline stem cells. Biol Reproduction 69: 612-616.

Kanatsu-Shinohara M, Takehashi M, Takashima S, Lee J, Morimoto H, Chuma S, Raducanu A, Nakatsuji N, Fassler R, Shinohara T. 2008. Homing of mouse spermatogonial stem cells to germline niche depends on beta1integrin. Cell Stem Cell 3: 533-542.

Kiger AA, Jones DL, Schulz C, Rogers MB, Fuller MT. 2001. Stem cell self-renewal specified by JAK-STATactivation in response to a support cell cue. Science 294: 2542-2545.

Kimble J. 2011. Molecular regulation of the mitosis/meiosis decision in multicellular organisms. Cold Spring Harb Perspect Biol doi: 10.1101/cshperspect.a002683.

Klattenhoff C, Theurkauf W. 2008. Biogenesis and germline functions of piRNAs. Development 135: 3-9.

Klein AM, Nakagawa T, Ichikawa R, Yoshida S, Simons BD. 2010. Mouse germ line stem cells undergo rapid and stochastic turnover. Cell Stem Cell 7: 214-224.

Kotaja N, Sassone-Corsi P. 2007. The chromatoid body: A germ-cell-specific RNA-processing centre. Nat Rev Mol Cell Biol 8: 85-90.

Kubota H, Avarbock MR, Brinster RL. 2004. Growth factors essential for self-renewal and expansion of mouse spermatogonial stem cells. Proc Natl Acad Sci 101: 1648916494.

Kugler JM, Lasko P. 2009. Localization, anchoring and translational control of oskar, gurken, bicoid and nanos mRNA during Drosophila oogenesis. Fly (Austin) 3: $15-28$.
LaFever L, Drummond-Barbosa D. 2005. Direct control of germline stem cell division and cyst growth by neural insulin in Drosophila. Science 309: 1071-1073.

Lawson KA, Hage WJ. 1994. Clonal analysis of the origin of primordial germ cells in the mouse. Ciba Found Symp 182: 68-84; discussion 84-91.

Lawson KA, Dunn NR, Roelen BA, Zeinstra LM, Davis AM, Wright CV, Korving JP, Hogan BL. 1999. Bmp4 is required for the generation of primordial germ cells in the mouse embryo. Genes Dev 13: 424-436.

Leatherman JL, Dinardo S. 2008. Zfh-1 controls somatic stem cell self-renewal in the Drosophila testis and nonautonomously influences germline stem cell self-renewal. Cell Stem Cell 3: 44-54.

Leatherman JL, Dinardo S. 2010. Germline self-renewal requires cyst stem cells and stat regulates niche adhesion in Drosophila testes. Nat Cell Biol 12: 806-811.

Le Bras S, Van Doren M. 2006. Development of the male germline stem cell niche in Drosophila. Dev Biol 294: 92-103.

Lee J, Kanatsu-Shinohara M, Inoue K, Ogonuki N, Miki H, Toyokuni S, Kimura T, Nakano T, Ogura A, Shinohara T. 2007. Akt mediates self-renewal division of mouse spermatogonial stem cells. Development 134: 1853-1859.

Li Y, Minor NT, Park JK, McKearin DM, Maines JZ. 2009. Bam and Bgcn antagonize Nanos-dependent germ-line stem cell maintenance. Proc Natl Acad Sci 106: $9304-$ 9309.

Lim AK, Kai T. 2007. Unique germ-line organelle, nuage, functions to repress selfish genetic elements in Drosophila melanogaster. Proc Natl Acad Sci 104: 6714-9719.

Lin H, Spradling AC. 1997. A novel group of pumilio mutations affects the asymmetric division of germline stem cells in the Drosophila ovary. Development 124: 2463-2476.

Lin MD, Jiao X, Grima D, Newbury SF, Kiledjian M, Chou TB. 2008. Drosophila processing bodies in oogenesis. Dev Biol 322: 276-288.

Liu N, Han H, Lasko P. 2009. Vasa promotes Drosophila germline stem cell differentiation by activating mei-P26 translation by directly interacting with a (U)-rich motif in its 3' UTR. Genes Dev 23: 2742-2752.

López-Onieva L, Fernandez-Minan A, Gonzalez-Reyes A. 2008. Jak/Stat signalling in niche support cells regulates dpp transcription to contol germline stem cell maintenance in the Drosophila ovary. Development 135: 533540.

Meng X, Lindahl M, Hyvonen ME, Parvinen M, de Rooij DG, Hess MW, Raatikainen-Ahokas A, Sainio K, Rauvala H, Lakso M, et al. 2000. Regulation of cell fate decision of undifferentiated spermatogonia by GDNF. Science 287: 1489-1493.

Molyneaux KA, Zinszner H, Kunwar PS, Schaible K, Stebler J, Sunshine MJ, O’Brien W, Raz E, Littman D, Wylie C, et al. 2003. The chemokine SDF1/CXCL12 and its receptor CXCR4 regulate mouse germ cell migration and survival. Development 130: 4279-4286.

Nakagawa T, Nabeshima Y-I, Yoshida S. 2007. Functional identification of the actual and potential stem cell compartments in mouse spermatogenesis. Dev Cell 12: $195-206$. 
Nakagawa T, Sharma M, Nabeshima Y, Braun RE, Yoshida S 2010. Functional hierarchy and reversibility within the murine spermatogenic stem cell compartment. Science 328: $62-67$.

Nakamura S, Kobayashi K, Nishimura T, Higashijima S, Tanaka M. 2010. Identification of germline stem cells in the ovary of the teleost medaka. Science 328: 1561-1563.

Neumuller RA, Betschinger J, Fischer A, Bushati N, Poernbacher I, Mechtler K, Cohen SM, Knoblich JA. 2008. Mei-P26 regulates microRNAs and cell growth in the Drosophila ovarian stem cell lineage. Nature 454: 241-245.

Nystul T, Spradling AC. 2007. An epithelial niche in the Drosophila ovary undergoes long-range stem cell replacement. Cell Stem Cell 1: 277-285.

Oakberg EF. 1956. Duration of spermatogenesis in the mouse and timing of stages of the cycle of the seminiferous epithelium. Am J Anat 99: 507-516.

Oakberg EF. 1971. Spermatogonial stem-cell renewal in the mouse. Anat Rec 169: 515-531.

Oatley JM, Avarbock MR, Telaranta AI, Fearon DT, Brinster RL. 2006. Identifying genes important for spermatogonial stem cell self-renewal and survival. Proc Natl Acad Sci 103: 9524-9529.

Oatley JM, Oatley MJ, Avarbock MR, Tobias JW, Brinster RL. 2009. Colony stimulating factor 1 is an extrinsic stimulator of mouse spermatogonial stem cell self-renewal. Development 136: 1191-1199.

Ohinata Y, Payer B, O'Carroll D, Ancelin K, Ono Y, Sano M, Barton SC, Obukhanych T, Nussenzweig M, Tarakhovsky A, et al. 2005. Blimp1 is a critical determinant of the germ cell lineage in mice. Nature 436: 207-213.

Park JK, Liu X, Strauss TJ, McKearin DM, Liu Q. 2007. The miRNA pathway intrinsically controls self-renewal of Drosophila germline stem cells. Curr Biol 17: 533-538.

Payne CJ, Gallagher SJ, Foreman O, Dannenberg JH, Depinho RA, Braun RE. 2010. Sin3a is required by sertoli cells to establish a niche for undifferentiated spermatogonia, germ cell tumors, and spermatid elongation. Stem Cells 28: $1424-1434$.

Pek JW, Lim AK, Kai T. 2009. Drosophila maelstrom ensures proper germline stem cell lineage differentiation by repressing microRNA-7. Dev Cell 17: 417-424.

Pepling ME, Spradling AC. 1998. Female mouse germ cells form synchronously dividing cysts. Development 125: 3323-3328.

Pepling ME, Spradling AC. 2001. Mouse ovarian germ cell cysts undergo programmed breakdown to form primordial follicles. Dev Biol 234: 339-351.

Rhiner C, Diaz B, Portela M, Poyatos JF, Fernandez-Ruiz I, Lopez-Gay JM, Gerlitz O, Moreno E. 2009. Persistent competition among stem cells and their daughters in the Drosophila ovary germline niche. Development 136: 995-1006

Sada A, Suzuki A, Suzuki H, Saga Y. 2009. The RNA-binding protein NANOS2 is required to maintain murine spermatogonial stem cells. Science 325: 1394-1398.

Sarkar A, Parikh N, Hearn SA, Fuller MT, Tazuke SI, Schulz C. 2007. Antagonistic roles of Rac and Rho in organizing the germ cell microenvironment. Curr Biol 17: $1253-$ 1258.
Schulz C, Wood CG, Jones DL, Tazuke SI, Fuller MT. 2002. Signaling from germ cells mediated by the rhomboid homolog stet organizes encapsulation by somatic support cells. Development 129: 4523-4534.

Seydoux G, Braun RE. 2006. Pathway to totipotency: Lessons from germ cells. Cell 127: 891-904.

Shen R, Weng C, Yu J, Xie T. 2009. eIF4A controls germline stem cell self-renewal by directly inhibiting BAM function in the Drosophila ovary. Proc Natl Acad Sci 106: 11623-11628.

Sheng XR, Brawley CM, Matunis EL. 2009a. Dedifferentiating spermatogonia outcompete somatic stem cells for niche occupancy in the Drosophila testis. Cell Stem Cell 5: 191-203.

Sheng XR, Posenau T, Gumulak-Smith JJ, Matunis E, Van Doren M, Wawersik M. 2009b. Jak-STAT regulation of male germline stem cell establishment during Drosophila embryogenesis. Dev Biol 334: 335-344.

Shivdasani AA, Ingham PW. 2003. Regulation of stem cell maintenance and transit amplifying cell proliferation by TGF-beta signaling in Drosophila spermatogenesis. Curr Biol 13: 2065-2072.

Song X, Call GB, Kirilly D, Xie T. 2007. Notch signaling controls germline stem cell niche formation in the Drosophila ovary. Development 134: 1071-1080.

Soper SF, van der Heijden GW, Hardiman TC, Goodheart M, Martin SL, de Boer P, Bortvin A. 2008. Mouse maelstrom, a component of nuage, is essential for spermatogenesis and transposon repression in meiosis. Dev Cell 15: 285-297.

Stevens LC. 1967. Origin of testicular teratomas from primordial germ cells in mice. $J$ Natl Cancer Inst 38: $549-552$.

Suzuki H, Sada A, Yoshida S, Saga Y. 2009. The heterogeneity of spermatogonia is revealed by their topology and expression of marker proteins including the germ cellspecific proteins Nanos2 and Nanos3. Dev Biol 336: 222-231.

Tadokoro Y, Yomogida K, Ohta H, Tohda A, Nishimune Y. 2002. Homeostatic regulation of germinal stem cell proliferation by the GDNF/FSH pathway. Mech Dev 113: 29-39.

Tilly JL, Niikura Y, Rueda BR. 2009. The current status of evidence for and against postnatal oogenesis in mammals: A case of ovarian optimism versus pessimism? Biol Reprod 80: 2-12.

Tulina N, Matunis E. 2001. Control of stem cell self-renewal in Drosophila spermatogenesis by JAK-STAT signaling. Science 294: 2546-2549.

Vincent SD, Dunn NR, Sciammas R, Shapiro-Shalef M, Davis MM, Calame K, Bikoff EK, Robertson EJ. 2005. The zinc finger transcriptional repressor Blimp1/ $\operatorname{Prdm} 1$ is dispensable for early axis formation but is required for specification of primordial germ cells in the mouse. Development 132: 1315-1325.

Von Stetina JR, Orr-Weaver TL. 2011. Developmental control of oocyte maturation and egg activation in metazoan models. Cold Spring Harb Perspect Biol doi:10.1101/ cshperspect.a005553. 
A. Spradling et al.

Voog J, D’Alterio C, Jones DL. 2008. Multipotent somatic stem cells contribute to the stem cell niche in the Drosophila testis. Nature 454: 1132-1136.

Voronina E, Seydoux G, Sassone-Corsi P, Nagamori I. 2011. RNA granules in germ cells. Cold Spring Harb Perspect Biol doi:10.1101/cshperspect.a002774.

Wang Z, Lin H. 2004. Nanos maintains germline stem cell self-renewal by preventing differentiation. Science 303: 2016-2019.

Wang L, Li Z, Cai Y. 2008. The JAK/STAT pathway positively regulates DPP signaling in the Drosophila germline stem cell niche. J Cell Biol 180: 721-728.

West JA, Viswanathan SR, Yabuuchi A, Cunniff K, Takeuchi A, Park IH, Sero JE, Zhu H, Perez-Atayde A, Frazier AL, et al. 2009. A role for Lin28 in primordial germ-cell development and germ-cell malignancy. Nature 460: 909-913.

White-Cooper H, Davidson I. 2011. Unique aspects of transcription regulation in male germ cells. Cold Spring Harb Perspect Biol doi:10.1101/cshperspect.a002626.

Woodruff TK. 2007. The emergence of a new interdiscipline: Oncofertility. Cancer Treat Res 138: 3-11.

Xia L, Jia S, Huang S, Wang H, Zhu Y, Mu Y, Kan L, Zheng W Wu D, Li X, et al. 2010. The Fused/Smurf complex controls the fate of Drosophila germline stem cells by generating a gradient BMP response. Cel1 143: 978-990.

Yamaji M, Seki Y, Kurimoto K, Yabuta Y, Yuasa M, Shigeta M, Yamanaka K, Ohinata Y, Saitou M. 2008. Critical function of Prdm14 for the establishment of the germ cell lineage in mice. Nat Genet 40: 1016-1022.

Yamashita YM, Fuller MT. 2005. Asymmetric stem cell division and function of the niche in the Drosophila male germline. Int J Hematol 82: 377-380.

Yamashita YM, Jones DL, Fuller MT. 2003. Orientation of asymmetric stem cell division by the APC tumor suppressor and centrosome. Science 301: 1547-1550.
Yamashita YM, Mahowald AP, Perlin JR, Fuller MT. 2007. Asymmetric inheritance of mother versus daughter centrosome in stem cell division. Science 315: 518-521.

Yang L, Chen D, Duan R, Xia L, Wang J, Qurashi A, Jin P. 2007a. Argonaute 1 regulates the fate of germline stem cells in Drosophila. Development 134: 4265-4272.

Yang L, Duan R, Chen D, Wang J, Chen D, Jin P. 2007b. Fragile $\mathrm{X}$ mental retardation protein modulates the fate of germline stem cells in Drosophila. Hum Mol Genet 16: 1814-1820.

Ying Y, Liu XM, Marble A, Lawson KA, Zhao GQ. 2000. Requirement of Bmp8b for the generation of primordial germ cells in the mouse. Mol Endocrinol 14: 10531063.

Yomogida K, Yagura Y, Tadokoro Y, Nishimune Y. 2003. Dramatic expansion of germinal stem cells by ectopically expressed human glial cell line-derived neurotrophic factor in mouse Sertoli cells. Biol Reprod 69: 1303-1307.

Yoshida S, Takakura A, Ohbo K, Abe K, Wakabayashi J, Yamamoto M, Suda T, Nabeshima Y-I. 2004. Neurogenin3 delineates the earliest stages of spermatogenesis in the mouse testis. Dev Biol 269: 447-458.

Yoshida S, Sukeno M, Nakagawa T, Ohbo K, Nagamatsu G, Suda T, Nabeshima Y. 2006. The first round of mouse spermatogenesis is a distinctive program that lacks the self-renewing spermatogonia stage. Development 133: 1495-1505.

Yoshida S, Sukeno M, Nabeshima Y. 2007. A vasculatureassociated niche for undifferentiated spermatogonia in the mouse testis. Science 317: 1722-1726.

Zou K, Yuan Z, Yang Z, Luo H, Sun K, Zhou L, Xiang J, Shi L, Yu Q, Zhang Y, et al. 2009. Production of offspring from a germline stem cell line derived from neonatal ovaries. Nat Cell Biol 11: 631-636. 


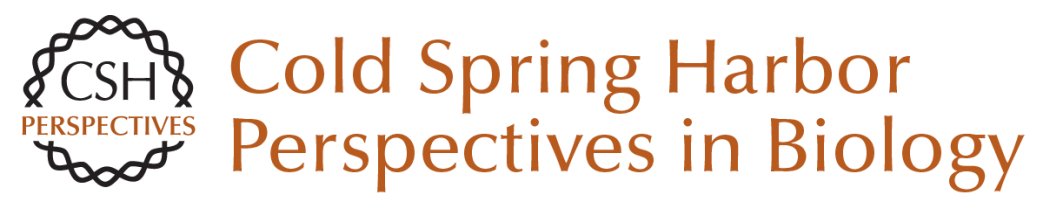

\section{Germline Stem Cells}

Allan Spradling, Margaret T. Fuller, Robert E. Braun and Shosei Yoshida

Cold Spring Harb Perspect Biol 2011; doi: 10.1101/cshperspect.a002642 originally published online July 26, 2011

\section{Subject Collection Germ Cells}

RNA Granules in Germ Cells

Ekaterina Voronina, Geraldine Seydoux, Paolo

Sassone-Corsi, et al.

Function of the Sex Chromosomes in Mammalian

Fertility

Edith Heard and James Turner

Small Noncoding RNAs in the Germline

Jonathan P. Saxe and Haifan Lin

Mammalian Genomic Imprinting

Marisa S. Bartolomei and Anne C. Ferguson-Smith

Molecular Regulation of the Mitosis/Meiosis

Decision in Multicellular Organisms Judith Kimble

Selection in the Rapid Evolution of Gamete Recognition Proteins in Marine Invertebrates Victor D. Vacquier and Willie J. Swanson
Developmental Control of Oocyte Maturation and

Egg Activation in Metazoan Models Jessica R. Von Stetina and Terry L. Orr-Weaver

Translational Control in Oocyte Development Joel D. Richter and Paul Lasko

Unique Aspects of Transcription Regulation in Male Germ Cells

Helen White-Cooper and Irwin Davidson

Germ Cell Intercellular Bridges

Michael P. Greenbaum, Tokuko Iwamori, Gregory M. Buchold, et al.

Germline Stem Cells

Allan Spradling, Margaret T. Fuller, Robert E. Braun, et al.

Nuclear Transfer to Eggs and Oocytes J. B. Gurdon and lan Wilmut

For additional articles in this collection, see http://cshperspectives.cshlp.org/cgi/collection/

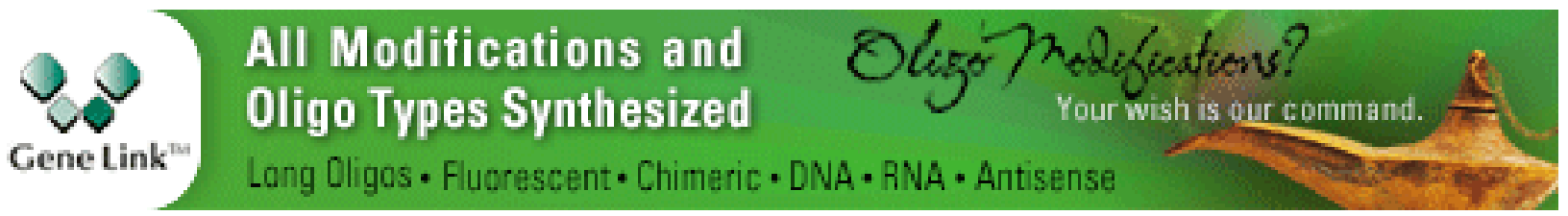

Copyright @ 2011 Cold Spring Harbor Laboratory Press; all rights reserved 